\title{
Epoxidation Modification of Renewable Lignin to Improve the Corrosion Performance of Epoxy Coating
}

\author{
Jiheng Ding ${ }^{1,2}$, Lin $G u^{1, *}$, Wei Dong ${ }^{2}$, Haibin $Y u^{1, *}$ \\ ${ }^{1}$ Key Laboratory of Marine Materials and Related Technologies, Key Laboratory of Marine Materials \\ and Protective Technologies of Zhejiang Province, Ningbo Institute of Materials Technology and \\ Engineering, Chinese Academy of Sciences, Ningbo 315201, P. R. China \\ ${ }^{2}$ School of Chemical Engineering, Nanjing University of Science and Technology, Nanjing 210094, P. \\ R. China \\ *E-mail: gulin195@gmail.com, haibinyu@ nimte.ac.cn
}

doi: $10.20964 / 2016.07 .56$

Received: 13 April 2016 / Accepted: 19 May 2016 / Published: 4 June 2016

\begin{abstract}
The epoxidation modification of renewable lignin was achieved by using epichlorohydrin under alkaline condition. Modified lignin (ELG) was characterized by FTIR and used to improve the corrosion performance of epoxy coatings. SEM images showed that ELG was well-dispersed in epoxy coatings, indicating that good compatibility of modified lignin with the epoxy resin. The anticorrosive properties of ELG/epoxy coatings coated on Q235 steel in 3.5\% $\mathrm{NaCl}$ solution were studied by polarization curves and electrochemical impedance spectroscopy (EIS). Compared with pure epoxy coating, the addition of ELG greatly improved the corrosion protection performance of Q235 steel. Especially, the epoxy coating with $2 \%$ ELG achieves high corrosion protection performance.
\end{abstract}

Keywords: lignin; epoxy resin; anticorrosion; Q235 Steel

\section{FULL TEXT}

(C) 2016 The Authors. Published by ESG (www.electrochemsci.org). This article is an open access article distributed under the terms and conditions of the Creative Commons Attribution license (http://creativecommons.org/licenses/by/4.0/). 